\title{
À Espera de um Desenvolvimento Sustentável
}

\section{Waiting for Sustainable Development}

Adriana Ripka ${ }^{1}$, Letícia Sayuri Kumegawa² e Christian Luiz da Silva ${ }^{3}$

1,2,3 Universidade Tecnológica Federal do Paraná, UTFPR

\section{Nota dos Autores}

O presente artigo foi apresentado no VII Simpósio Nacional de Ciência, Tecnologia e Sociedade VII ESOCITE.BR/tecsoc, em Brasília, no grupo de trabalho 04 - Políticas públicas e desenvolvimento local: interveniências e interações entre tecnologia, sociedade e democracia. 


\title{
Resumo
}

Desenvolvimento sustentável é um termo considerado recente na literatura, tendo o seu primeiro registro em 1987, no Relatório de Brundtland. Contudo, os elementos que envolvem a essência do termo, como limitação dos recursos naturais e a relação consumo e natureza, são discutidos a mais tempo, desde a década de 1960. Apesar da aceitabilidade do termo, ou seja, inclusão na pauta de discussão dasáreas e o aumento de estudos sobre o tema, se encontram críticas quanto às ações insuficientes, e até ineficientes, no sentido de se alcançar o desenvolvimento sustentável. Nesse contexto, o este artigo objetiva analisar o desenvolvimento sustentável relacionado às políticas públicas e aos estudos de Ciência, Tecnologia e Sociedade. Para tanto, teve-se como base a análise de textos pertinentes ao tema, resultando em um artigo construído a partir de pesquisa bibliográfica. Como resultado foi verificar que os estudos de Ciência, Tecnologia e Sociedade possuem papel importante no surgimento do desenvolvimento sustentável e que as políticas públicas são ferramentas que podem executar ações em prol da causa. No entanto, apesar de o desenvolvimento sustentável receber cada vez mais atenção nas pautas de discussões, a prática efetiva tem deixado a desejar trazendo a ideia de que se espera alcançar o desenvolvimento sustentável mesmo com a manutenção de ações que se mostram insustentáveis a longo prazo.

Palavras-chave: desenvolvimento sustentável, políticas públicas, ciência, tecnologia e sociedade

\begin{abstract}
Sustainable development is a term considered recent in the literature, having its first record in 1987 in the Brundtland Report. However, the elements that involve the essence of the term, such as the limitation of natural resources and the relation between consumption and nature, have been discussed for much longer since the 1960s. Despite the great acceptability of the term, the inclusion in the discussion agenda of several areas and the increase of studies on the subject, are critically expressive of insufficient and even inefficient actions to achieve sustainable development. In this context, this article aims to analyze the sustainable development related to Public Policies and Science, Technology and Society studies. In order to achieve this goal, it was based on the analysis of texts pertinent to the theme, thus dealing with an article constructed from bibliographical research. As a result, it was verified that the studies of Science, Technology and Society play an important role in the emergence of sustainable development and that public policies are tools that can carry out actions in favor of the cause. However, despite the fact that sustainable development is receiving increasing attention in the discussions, effective practice has been not as desired, bringing the idea that it is hoped to achieve sustainable development even with actions that are unsustainable in the long run.
\end{abstract}

Keywords: sustainable development, public policy, science, technology and society 
Em uma breve pesquisa em livros, artigos e internet, sobre temas variados, pode-se observar que ciência e tecnologia (C\&T) são termos recorrentes em discursos, contudo, de forma geral, pode-se dizer que o conceito atribuído a estes dois termos varia de acordo com o contexto e a subjetividade do interlocutor, que transborda em seu discurso seu conhecimento adquirido e de seu entendimento do que é ciência e o que é tecnologia.

De acordo com Cerezo (2004), sob uma visão essencialista e triunfalista, assume-se que quanto mais ciência, mais tecnologia e isso resulta em maior bem-estar social. Trata-se de uma abordagem determinista, na qual a sociedade é apenas beneficiada pelo incremento da ciência e tecnologia, e que considera estas como neutras, ou seja, sem que tenham nenhuma relação com as necessidades da sociedade, e consequentemente, sem relação com a cultura desta.

A partir desta visão, são registrados grandes investimentos em ciência e tecnologia, principalmente, no período de reconstrução pós-guerra. Contudo, o otimismo mostrou-se crescente somente até meados da década de 1950, quando impactos negativos começaram a ser percebidos e atribuídos ao aumento do uso indiscriminado de tecnologia (Cutcliffe, 2003; Cerezo, 2004). Segundo Cutcliffe (2003), foi na década de 1960 que surgiram, no âmbito acadêmico, os estudos de Ciência, Tecnologia e Sociedade (CTS) os quais levantaram questionamentos que levaram ao reconhecimento da existência de impactos negativos da tecnologia, tanto na sociedade quanto no meio ambiente.

Levantados os questionamentos, passa-se a uma mudança na interpretação da ciência e tecnologia, considerando-as não mais autônomas da sociedade, mas passíveis de influência, como pela dimensão socioambiental e ao mesmo tempo capaz de influenciá-la, não só positivamente, mas também de forma negativa (Cerezo, 2004). Este é um ponto relevante quanto ao termo Desenvolvimento Sustentável e o que é explorado na construção deste artigo.

De acordo com Kreimer (2009), a questão do desenvolvimento é um tema complexo, dado que envolve elementos como recursos naturais, história, cultura e a estrutura de cada sociedade. Contudo, o autor ainda destaca que, em anos anteriores, esta questão foi amplamente simplificada a modelos, os quais deveriam ser fielmente reproduzidos para se alcançar o desenvolvimento, desconsiderando assim toda a especificidade de cada país, bem como a complexidade envolvida. À tal simplificação pode-se comparar a visão determinista da ciência e tecnologia, dado que apresenta uma ideia de trajetória linear, com a expectativa de um inquestionável resultado positivo.

A partir disso, pode-se assumir que os questionamentos advindos da pesquisa acadêmica, e dos movimentos sociais, sobre a visão determinista, no que diz respeito à ciência e à tecnologia, ampliou o papel atribuído à sociedade, emergindo um campo específico denominado Ciência, Tecnologia e Sociedade (CTS). Já sobre o questionamento do modelo linear de desenvolvimento, a complexidade citada por Kreimer (2009) passa a ser considerada a partir do momento em que se começa a reconhecer a mútua influência entre os diversos elementos que compõem o modelo, movimento estimulado pelos estudos de CTS. No entanto, apesar de tais discussões se iniciarem, e se fortalecerem, entre os anos de 1960 e 1970, e ter em pauta a preocupação com a sustentabilidade, 
ou seja, "o processo de reconciliação do desenvolvimento com a conservação da biodiversidade" (Sachs, 2002, p. 72), foi apenas em 1987 que o termo desenvolvimento sustentável foi definido pela primeira vez (Van Bellen, 2006).

Os estudos de CTS são elemento fundamental no que se refere ao surgimento do conceito de Desenvolvimento Sustentável. Este, por sua vez, tem sido cada vez mais aclamado nos discursos políticos, sociais, empresariais e ecológicos/ambientais, ao mesmo tempo em que é colocado, de forma contraditória, como um empecilho ao progresso de tecnologias reconhecidas como poluentes (poluição do ar, da água e do solo, geração de resíduos, degradação do meio ambiente em geral), ou mesmo contra determinadas culturas, quando se limita tradições centenárias, ou até milenares. Como por exemplo, na cidade de San Vitaliano, localizada no sul da Itália, cujas autoridades locais proibiram o uso de forno à lenha como forma de conter a poluição, a ação repercutiu como prejudicial à tradição dos preparos de pratos típicos, como a pizza assada em forno à lenha (BBC, 2015).

Um problema identificado, nas referências analisadas para a construção deste artigo, é que o discurso elaborado com o simples objetivo de se atender as expectativas dos ouvintes, neste caso, discursar que se deve buscar o desenvolvimento sustentável, na prática não se realiza com a mesma vivacidade com a qual é pronunciada. Dessa forma, essa diferença entre o discurso e a prática pode se transformar em uma "longa espera", por parte da sociedade, a qual tem uma promessa da busca de um caminho sustentável, mas não tem um prazo para realização de tal busca de forma efetiva.

Diante do exposto, com a construção deste artigo, tem-se como objetivo analisar o desenvolvimento sustentável relacionado às políticas públicas e aos estudos de Ciência, Tecnologia e Sociedade.

Para tanto, pretende-se inicialmente elencar os fatores que estimularam a inclusão do termo desenvolvimento sustentável na atual discussão, considerando que as trajetórias cultural e histórica influenciam nas ações atuais da sociedade. Neste sentido, recorre-se à bibliografia relacionada aos estudos de CTS, como as citadas brevemente nesta introdução, se valendo de conceitos como os de abordagem construtivista, com base em autores como Bijker et al. (1989), Hughes (1989), Feenberg (2007; 2010) e Neder (2010). São analisados, ainda, referências ligadas ao desenvolvimento sustentável, como Sachs (2002), Van Bellen (2006) e Boff (2015), entre outros, e referências ligadas às políticas públicas, como Souza (2006) e Cavalcanti (2001), entre outros autores.

\section{A Origem do Desenvolvimento Sustentável a partir dos Estudos de Ciência, Tecnologia e Sociedade}

Como apresentado por Cerezo (2004), a ciência e tecnologia, principalmente no período pós-guerra, ganharam destaque como elementos essenciais ao desenvolvimento e dotados da capacidade de gerar somente benefícios à sociedade. Tal visão de caráter essencialista, ou determinista, ganhou nova perspectiva a partir da década de 1960 com os estudos de Ciência, Tecnologia e Sociedade (CTS). Ainda de acordo com Cerezo (2004, p. 17), "[...] os estudos de CTS foram se adiantando como uma alternativa à reflexão tradicional em filosofia e sociologia da ciência, promovendo uma nova visão não essencialista e contextualizada da atividade científica como processo social".

Tal alternativa de pensamento, além de trazer à discussão a sociedade como um agente capaz de, mutuamente, influenciar e ser influenciado pela ciência e pela tecnologia, possibilitou não só reconhecer a 
existência de externalidades negativas como relacioná-las ao incremento científico-tecnológico, ocorrido em período anterior. Segundo Cutcliffe (2003), tal incremento na utilização de tecnologia funcionou como uma forma "inquestionável" de se resolver os problemas do pós-guerra, mas foram os estudos de CTS que revelaram os impactos negativos da tecnologia, tanto na sociedade quanto no meio ambiente. A liderança de tal movimento atribui-se aos acadêmicos, escritores e críticos ativistas, cujas preocupações se estendiam a áreas como direito, energia, meio ambiente e outras demandas de motivação pública, ou seja, expandindo para além das áreas de engenharias e exatas (Cutcliffe, 2003).

Essa relação antideterminista, que consequentemente nega teorias essencialistas, substantivistas e a-históricas - as quais rejeitam o poder dos movimentos sociais e a influência histórica e social - passa a ser identificada como construtivista (Neder, 2010). O construtivismo, como pode se intuir diante do que já foi aqui exposto, se opõe à ideia de linearidade no desenvolvimento tecnológico, podendo este também retroceder a uma tecnologia que seja compatível à necessidade da sociedade atual e descarta a neutralidade da tecnologia, dado o reconhecimento da influência de fatores sociais na construção desta (Neder, 2010).

Das teorias alinhadas a essa perspectiva construtivista pode-se citar a Construção Social da Tecnologia (Social Construction of Technology - SCOT) de Trevor Pinch e Wiebe Bijker (Bijker et al., 1989) e o Sistema Tecnológico de Hughes (1989). Ambas trazem o aumento da complexidade na tomada de decisão seja de criação, implantação ou modificação de um elemento tecnológico e podem ser relacionadas ao planejamento visando alcançar o desenvolvimento sustentável, o qual é definido como "aquele que atende as necessidades das gerações atuais sem comprometer a capacidade das gerações futuras de atenderem as suas necessidades e aspirações" (Boff, 2015, p. 34).

A SCOT é apresentada pelos seus autores, em Bijker et al. (1989), a partir de um modelo multidirecional (não linear), destacando o "grupo social relevante" e a "flexibilidade interpretativa" como principais elementos deste modelo. O grupo social relevante é formado por membros que apresentam similaridade no significado que atribuem a uma determinada tecnologia, podendo existir vários grupos, com diferentes significados, avaliando uma mesma tecnologia. A estes grupos é atribuída a responsabilidade de identificar problemas, necessidades, adaptabilidade e outras características que podem levar à aceitação, modificação ou rejeição de uma tecnologia. Dada a existência de grupos com significados diferentes para uma mesma tecnologia, as características apontadas pelos grupos podem ser diferentes, ou mesmo conflitantes, e para isso a flexibilidade interpretativa tem como função permitir a ponderação, mediação e avaliação das características, viabilizando a tomada de decisão (Bijker et al., 1989).

De forma similar, o Sistema Tecnológico de Hughes (1989) trata-se de um sistema complexo, o qual envolve a interação de elementos físicos (como tecnologia e recursos naturais) e não físicos (como conhecimento científico e artefato legislativo e político), cuja importância é equivalente entre os tipos de elemento. Neste sistema as interações podem ser diretas e indiretas e a alteração, inclusão ou exclusão de qualquer elemento gera adaptação 
em todos os outros elementos do sistema. Quando o sistema se mantém sem alterações, ou seja, com os elementos constantes, Hughes atribui o nome de Momentum.

Tanto a SCOT quanto o Sistema Tecnológico são teorias que permitem dimensionar, minimamente, a complexidade que os estudos de CTS atribuíram à tecnologia. Complexidade adquirida com a inclusão de áreas de conhecimento relevantes à sociedade, que antes dos estudos de CTS eram desconsideradas quando se tratava de ciência e tecnologia. Esta inclusão acabou por contribuir para a necessidade de uma visão interdisciplinar dos estudos, exigindo dos pesquisadores uma formação mais ampla, o que refletiu em movimentos sociais e estudos que propiciaram se pensar nas limitações naturais, não só para a sociedade presente, mas também para a futura, o que é a base do desenvolvimento sustentável (Gibbons et al., 1994).

Dentre as necessidades da sociedade, os recursos naturais são elementos fundamentais para a manutenção, ou incremento, do padrão de consumo. Sobre o tema, Feenberg (2007) destaca que a teoria do trade off - na qual se abre a mão de um bem ou serviço em prol de se obter outro - não deve ser considerada a única forma de se tomar uma decisão, diante de uma situação de problema, deve-se avaliar também outras possibilidades, como sugere a relatividade social da eficiência, ou seja, buscar um aumento de eficiência que minimize os danos causados pela tecnologia no meio ambiente e na sociedade.

De forma geral, ao se "desvendar os olhares" da sociedade, como um todo, para uma nova forma de se entender a ciência e a tecnologia, os estudos de CTS possibilitaram questionamentos sobre os benefícios e malefícios envolvidos na adoção de uma tecnologia. Tais questionamentos estimularam o aprofundamento de estudos que resultaram, por exemplo, no livro Silent Spring, de Rachel Carson (1962), e do Limits to Growth, de Donella Meadows et al. (1972), os quais, entre outros, embasaram a preocupação com questões socioambientais e consequentemente do desenvolvimento sustentável.

Contudo, apesar de se reconhecer os problemas ligados ao tema, se estudar e almejar soluções para estes, que podem partir da SCOT, do Sistema Tecnológico, da relatividade social da eficiência, dentre outros conteúdos, é a execução de ações que pode, em realidade, combater um problema identificado. No caso do desenvolvimento sustentável como objetivo, a política pública pode ser um elemento contribuinte para este resultado.

\section{A Política Pública e a Política Científica e Tecnológica}

De acordo com Dias (2011), a política pública é facilmente compreendida "como uma ação ou conjunto de ações por meio das quais o Estado interfere na realidade, geralmente com o objetivo de atacar algum problema" (Dias, 2011, p. 319). Tal compreensão se fundamenta nos conceitos aplicados à política pública por diversos autores que, apesar das diversas redações para defini-la, acabam por relacionar termos como, por exemplo, governo, ação, escolha e questões públicas. Destes conceitos é que surge a possibilidade de a política pública contribuir para o desenvolvimento sustentável, no entanto, a crítica à forma de elaboração e execução da política pública é que embasa a outra possibilidade, a de não contribuir ou até prejudicar.

Dentre algumas das definições de política pública, Dias (2011) destaca uma citação direta de Souza (2006), a qual afirma que: 
Não existe uma única, nem melhor, definição sobre o que seja política pública. Mead (1995) a define como um campo dentro do estudo da política que analisa o governo à luz de grandes questões públicas e Lynn (1980), como um conjunto de ações do governo que irão produzir efeitos específicos. Peters (1986) segue o mesmo veio: política pública é a soma das atividades dos governos, que agem diretamente ou através de delegação, e que influenciam a vida dos cidadãos. Dye (1984) sintetiza a definição de política pública como "o que o governo escolhe fazer ou não fazer". A definição mais conhecida continua sendo a de Laswell (1958), ou seja, decisões e análises sobre política pública implicam responder às seguintes questões: quem ganha o quê, por quê e que diferença faz (Souza, 2006, p. 24).

Indiferente da definição observada, pode-se verificar a presença dos elementos ação e escolha. Sendo assim, para estes, o conhecimento sobre os aspectos da sociedade e a compreensão da complexidade das interações, destacada nos estudos de CTS, fomentam o processo decisório. No entanto, se deve ressaltar que não necessariamente as decisões levam à solução dos problemas identificados.

De acordo com Cerezo (2004, p. 18) "no campo da política pública, os estudos CTS têm defendido a regulamentação pública da ciência e tecnologia, promovendo a criação de diversos mecanismos democráticos que facilitem a abertura dos processos de tomada de decisão em questões concernentes a políticas científicotecnológicas". Um destes mecanismos, conceitualmente, pode ser citado como a política científica e tecnológica.

A política científica e tecnológica (PCT), segundo Dias (2011, p. 325), "é singular porque compreende muito mais do que a simples alocação de recursos públicos: envolve também a moldagem das formas com que as pessoas interpretam socialmente quem são e o que é real e importante, por meio do conhecimento científico e tecnológico". Trata-se de uma política que serve de apoio para políticas públicas de diversas áreas, que envolvam ciência e tecnologia (C\&T), como por exemplo a industrial, a agrícola, a educacional etc.

Criada em período anterior à discussão sobre o desenvolvimento sustentável, a PCT impulsionou o investimento em C\&T, sob a visão determinista no que se refere a estes elementos. Dentre as características percebidas na PCT, Dias (2011) destaca a preocupação com a oferta de conhecimento e de profissionais qualificados; o estímulo ao vínculo entre universidades e empresas; e a emulação de experiência estrangeira de forma acrítica. A credibilidade cega na C\&T possibilitou o avanço da PCT no sentido de alcançar o desenvolvimento em diferentes áreas, em geral atendendo interesses de classes específicas da sociedade.

O distanciamento histórico da C\&T da sociedade, ou seja, a negação de que a sociedade pode participar de decisões ligadas ao tema, é refletida na PCT, que apesar de viabilizar um canal capaz de direcionar recursos e ressaltar problemas relevantes da sociedade, acaba por manter, na prática, os interesses de poucos atores em foco. Sobre o caso específico do Brasil, Dias (2011) cita que:

Foi essa posição hegemônica que ocupa a comunidade de pesquisa no âmbito da PTC brasileira o fator que possibilitou que a essência dessa política se mantivesse estável desde sua institucionalização. É verdade que hoje ela se mostra muito mais sofisticada: elementos como a inovação tecnológica, a competitividade empresarial (e, por indevida extensão, nacional) e a figura da empresa privada estão cada vez mais 
presentes nos documentos oficiais e mesmo nas reflexões acadêmicas sobre política científica e tecnológica (Viotti, 2008). Essa aparente sofisticação do discurso não deve, contudo, ser confundida com uma mudança significativa no conteúdo da política. Ela é, de fato, parte da estratégia (em grande parte, não intencional e inconsciente) da comunidade de pesquisa no sentido de garantir a continuidade. Assim, o discurso mudou para que a agenda da política não tivesse que fazê-lo (Dias, 2011, p. 333 - 334).

Em outras palavras, a percepção essencialista da ciência e da tecnologia mostrou-se presente na institucionalização da PCT e, apesar das discussões de CTS trazerem uma reflexão que inclui muitos outros atores (antes ignorados) nos sistemas observados, pouco se observa de mudanças práticas neste sentido. E com responsabilidade parcial desta continuidade podemos destacar, como na citação acima, "em grande parte, não intencional e inconsciente" a comunidade de pesquisa.

Nos discursos apresentados aqui, até o momento, cabe como reflexão citar que apesar de a política pública ter em seu conceito, nas diversas definições, elementos como ações, escolhas, questões sociais muitas vezes se dissociam da teoria na prática. Tal afastamento deve-se às etapas envolvidas na elaboração e aplicação da política pública. Da mesma forma, na PCT "como em outras políticas, o discurso nem sempre reflete claramente o que se pretende fazer na prática" (Dias, 2011, p. 335).

Neste sentido, e associado ao tema deste artigo, Cavalcanti (2001, p. 3) afirma que "a despeito de uma retórica (em época mais recente) de sustentabilidade da parte do governo, o que tem prevalecido são iniciativas que não levam propriamente a natureza em consideração (O termo natureza deve ser entendido no sentido de meio ambiente, dado o contexto da qual foi retirada esta citação) e isto pode ser verificado na elaboração de política pública. A prioridade dada a alguns elementos, e não a outros, no momento de se colocar em prática uma política pode ser compreendida à medida que entendemos sob quais bases estas são elaboradas.

Das fases envolvidas na elaboração de política pública pode-se destacar a partir de Dias (2011): a elaboração da agenda, que corresponde ao tema prioritário a ser confrontado ou estimulado; o mapa, que são as agendas do Estado; o jogo político, orientação política do momento histórico; a arquitetura do poder, que atua na determinação dos temas da agenda; e os conflitos latentes, que quando não percebidos pelos atores mais fracos (o que acontece na maioria das vezes) preservam a condição dos mais fortes (classe dominante).

Para Cavalcanti (2001) este modelo de elaboração de política pública vai contra o objetivo de se alcançar o desenvolvimento sustentável, pois, à medida que os interesses da classe dominante, dotada de poder, se sobrepõem aos interesses da sociedade em geral, apenas se reforçam as desigualdades sociais, e consequentemente se preserva a pobreza da maioria, prejudicando qualquer sistema de desenvolvimento que se idealize sustentável no longo prazo.

Viera Pinto (2005) sugere a compreensão da tecnologia a partir da própria complexidade e das relações desta com a política da sociedade. Contemplando esta perspectiva ao se analisar a tecnologia, a partir da estrutura da política pública e consequentemente da PCT, pode-se assumir que, apesar de o discurso ter sofrido alterações ao longo do tempo, desde o início dos estudos de CTS, a prática para se alcançar o desenvolvimento sustentável 
carece de mudanças profundas. Isso se deve ao fato de, na estrutura política, elementos como poder e jogo político, comumente associados às classes dominantes, influenciarem a construção da agenda, pois em geral são as demandas de poucos que se sobrepõem às demandas reais da sociedade.

\section{O Desenvolvimento Sustentável e suas Barreiras para se Avançar para Além do Discurso}

Como visto até o momento, os estudos de Ciência, Tecnologia e Sociedade (CTS) tiveram papel relevante na origem do desenvolvimento sustentável. Embasando-o com estudos que resultaram em livros como o Silent Spring (1962) e o Limits to Growth (1972). Já com relação à política pública, mais especificamente à política científica e tecnológica (PCT), esta apresenta um direcionamento para a área de ciência e tecnologia (C\&T), o que poderia viabilizar o desenvolvimento sustentável, mas dado o distanciamento entre a prática e o discurso acaba por reforçar parâmetros anteriores à discussão de desenvolvimento sustentável.

Segundo Van Bellen (2006), não há um conceito único para o termo desenvolvimento sustentável, apesar do seu surgimento e a sua compreensão geral partir do Relatório de Brundtland, a adaptação do termo a cada objetivo e a cada discurso pode trazer um número significativo de interpretações distintas. Tais diferenças de ponto de vista podem ser um elemento que contribua para que a aplicação do discurso, em prol de se alcançar a sustentabilidade, seja protelada.

Outro ponto destacado, no texto de Van Bellen (2006), é a dependência que se tem aos tradicionais dados quantitativos para o planejamento e avaliação de projetos. Em se tratando de desenvolvimento sustentável, este apresenta dificuldades de mensuração. Tais dificuldades podem ser atribuídas, por exemplo: à inexistência de coleta de dados ao longo da história de algumas variáveis, que antes tinham sua existência ignorada; ao fato de se subestimar dados, como por exemplo uma empresa que pode alterar medidores de emissão de $\mathrm{CO}_{2}$ (dióxido de carbono) em seus produtos, com o intuito de evitar penalidades, ou mesmo, para se beneficiar de uma imagem de empresa apoiadora do desenvolvimento sustentável; à dificuldade de se interpretar dados qualitativos, que pode levar a uma tendência em se tentar os converter grosseiramente em números, minimizando a riqueza de informações que estes possam trazer, ou ainda, apresentar interpretações dotadas de parcialidade, ou seja, de forma que o resultado da análise dos dados sustente o interesse de atores da classe dominante.

Ao se considerar que para a elaboração de políticas públicas os números (dados quantitativos), carregados de conceitos econômicos, sempre foram fatores relevantes na tomada de decisão, no que diz respeito ao "o que fazer e o que deixar de fazer", se pode assumir que a dificuldade em se coletar e interpretar os dados associados ao desenvolvimento sustentável é um fator que pode ser considerado como uma das barreiras a se transpor, para que o discurso seja refletido na realidade.

Sachs (2002), como forma de viabilizar a compreensão de como se alcançar o desenvolvimento sustentável, divide tal objetivo em dimensões de análise: a dimensão econômica; a dimensão social; a dimensão ambiental; a dimensão espacial/geográfica; e a dimensão cultural. Quando analisadas individualmente, cada uma dessas dimensões, como há de se esperar, possui características, problemas e objetivos específicos. Contudo, para que seja 
possível o desenvolvimento sustentável, o autor ressalta que os diferentes objetivos de cada dimensão de análise devem ser complementares uns aos outros e não competir entre si.

As dimensões de análise, citadas acima, podem contribuir para a compreensão de elementos que devem ser cogitados na elaboração de uma política, trazendo as preocupações apontadas nos estudos de CTS, como, por exemplo, as questões sociais e culturais. Contudo, a análise segmentada pode trazer prejuízos, que podem ocorrer se houver a sobreposição dos interesses entre grupos com uma relação mais consolidada a uma ou outra dimensão. Nos textos de Bijker et al. (1989), Hughes (1989), Feenberg (2007; 2010) e Neder (2010), por exemplo, de forma geral, respeitando os contextos diversos, se pode observar que apesar se ter ampliado o número de variáveis a serem observadas em situações de planejamento e de tomada de decisão, o interesse de classes dominantes pode se sobrepor a problemas da sociedade atual, protelando ou até minimizando as chances de solução.

A flexibilidade interpretativa, citada na apresentação da SCOT, é um elemento que, em teoria, poderia contribuir para se alcançar a complementariedade dos objetivos de diferentes dimensões de análise, dado que com ela se poderia mediar os conflitos. Contudo, pensando na elaboração de uma política científica e tecnológica, por exemplo, dada a restrição quanto a diversidade dos atores envolvidos na elaboração da agenda, com a participação mínima de atores da sociedade (quanto existente), em geral os conflitos diretamente ligados a problemas reais da sociedade acabam sendo reduzidos e até mesmo ocultos na discussão. Com isso se pode destacar, assim, o poder de decisão de uma classe dominante, se retomarmos os textos de Dias (2011) e Souza (2006), dentre outros.

Sobre uma perspectiva similar à visão de Sachs (2002), de segmentação de análise do que se é considerado necessário para se alcançar o desenvolvimento sustentável, de acordo com Boff $(2015$, p. 43) alguns teóricos relevantes destacam que "para ser sustentável o desenvolvimento deve ser economicamente viável, socialmente justo e ambientalmente correto". Contudo o próprio autor tece crítica ao desenvolvimento sustentável considerando estes elementos, citando problemas como: a existência de uma visão antropocêntrica; a existência de contradição; e a existência de equívoco.

Contextualizado no sistema capitalista, Boff (2015) explica que o termo desenvolvimento está centrado apenas no ser humano, não tratando este como parte de um sistema maior, envolvendo outros elementos como seres vivos e recursos da natureza, e sim mantendo-o como foco, ou seja, um modelo antropocêntrico. Este ponto não se alinha, por exemplo, com o Sistema Tecnológico de Hughes, que indica que todos os elementos do sistema, elementos físicos e não físicos, tenham o mesmo peso.

No que se refere à contradição, Boff (2015) destaca que nos termos desenvolvimento e sustentável são seguidas lógicas diferentes. De acordo com o autor, isso se deve à compreensão, de desenvolvimento como uma busca linear e de exploração crescente da natureza, incorrendo em desigualdades sociais resultantes da acumulação individual de riquezas, o que vai contra a ideia de sustentabilidade.

O fato de citar a existência de equívoco na compreensão de desenvolvimento sustentável, apresentado por Boff (2015), se deve ao fato de se atribuir, comumente, a degradação do meio ambiente à pobreza. Isso porque, a relação é desvendada pelo autor como sendo inversa, ou seja, o modelo de desenvolvimento vigente, que tem 
como base a exploração indiscriminada dos recursos naturais, com a consequente degradação do meio ambiente, e a exploração da força de trabalho, por pagamento de baixos salários e exclusão social, é que é responsável pela pobreza e não a pobreza pela degradação dos recursos naturais.

Pode-se considerar, a partir do exposto, que:

[...] a utilização política da expressão desenvolvimento sustentável apresenta uma armadilha no sistema operante: assume os termos da ecologia (sustentabilidade) para esvaziá-los e assume o ideal da economia (crescimento / desenvolvimento), mascarando, porém, a pobreza que ele mesmo produz (Boff, 2015, p. 46). Esta citação, ao tratar a utilização do termo desenvolvimento sustentável como dotada de uma armadilha, explicita o fato de que, apesar de os estudos e esforços em se questionar a existência de apenas benefícios nas tomadas de decisões, envolvendo a escolha de uma tecnologia por exemplo, o discurso tem se "adaptado aos ouvidos", mas a "prática não tem se mostrado aos olhos".

Boff (2015) ainda reforça este ponto ao dizer que:

[...] a utilização da expressão 'desenvolvimento sustentável' possui uma significação política importante: representa uma maneira hábil de desviar a atenção para os reais problemas, que são a injustiça social nacional e mundial, o aquecimento global crescente e as ameaças que pairam sobre a sobrevivência de nossa civilização e da espécie humana (Boff, 2015, p. 48).

A expressão "maneira hábil de desviar a atenção para os problemas reais", na citação anterior, destaca um ponto essencial ao título deste artigo, "à espera de um desenvolvimento sustentável". Isso porque, como apresentado ao longo deste artigo, é fato que o modelo de desenvolvimento que se tem praticado, nas últimas décadas, se mostra insustentável no longo prazo, dado o reconhecimento de limitações naturais para a manutenção deste processo de forma crescente, no entanto, ao se adicionar, aos discursos, elementos que demonstrem que preocupação com tais problemas se desperta a ideia de que, na prática, está se caminhando para um desenvolvimento sustentável.

Em realidade, a escolha controlada dos problemas relevantes para a sociedade, na elaboração de políticas públicas, permite que sejam feitos pequenos avanços - como a redução da emissão de carbono, uso de energias alternativas, reflorestamento, entre outros - nos objetivos em prol da sustentabilidade, desde que, com estes, "não se afetem os lucros, não se enfraqueça a competição e não se prejudiquem as inovações tecnológicas" (Boff, 2015, p. 48), estando este último ponto entre as principais preocupações das políticas científica e tecnológica.

Em outras palavras, o discurso apresentado em estudos, em eventos, e até em textos envolvendo política pública, e outros, revela as limitações com relação aos recursos naturais e os problemas relacionados ao processo de um desenvolvimento crescente nos moldes atuais, bem como a insustentabilidade deste. Desta forma, tal discurso contribui para se criar a ilusão de que se está colocando em prática ações efetivas para se alcançar o desenvolvimento sustentável, ao passo que na realidade está se utilizando tal discurso apenas para distrair a atenção de atores que poderiam interferir, principalmente, na lucratividade da classe dominante. Em conclusão, 
Boff $(2015$, p. 47) reforça este ponto ao citar que "no modelo padrão de desenvolvimento que se quer sustentável, o discurso da sustentabilidade é vazio e retórico".

Os adjetivos vazio e retórico, que são atribuídos ao discurso, transparecem a principal barreira que restringe o desenvolvimento sustentável em avançar para além do discurso, pois, sem que a complexidade das inter-relações do sistema apresentado nos estudos de CTS sejam trabalhadas na prática, dado que a ciência e tecnologia são reconhecidos como fatores essenciais ao desenvolvimento, a sociedade permanecerá na ilusão de poder se alcançar algo que na realidade se torna cada dia mais distante. Tem-se que agir de forma coerente ao reconhecimento que "um planeta finito não suporta um projeto infinito" (Boff, 2015, p. 42) e para que se cesse essa "eterna espera" de um desenvolvimento sustentável as ações têm que se fazer efetivas, no sentido de se mudar realmente as ações do presente para se alterar o cenário anunciado.

\section{Considerações Finais}

O presente artigo, com o objetivo de analisar o desenvolvimento sustentável relacionado às políticas públicas e aos estudos de Ciência, Tecnologia e Sociedade (CTS), se utilizando da análise de textos pertinentes aos temas envolvidos, possibilitou o reconhecimento de que os estudos de Ciência, Tecnologia e Sociedade (CTS) possuem papel importante no surgimento do desenvolvimento sustentável.

A visão não determinista da ciência e da tecnologia (C\&T) foi fundamental para o reconhecimento da existência das externalidades negativas, envolvidas na discussão sobre as limitações do meio ambiente. Sem este reconhecimento, provavelmente, não seria possível se cogitar a necessidade de se pensar em alternativas ao modelo de desenvolvimento baseado apenas em crescimento. Como externalidades negativas da C\&T se pode citar a poluição do ar, da água e do solo, a degradação do meio ambiente, a geração de resíduos, entre outros, e estes revelam o equívoco em se assumir que mais C\&T resulta em maior bem-estar social.

A inexistência de neutralidade da tecnologia, ou seja, ela influencia e é influenciada de forma simultânea pelo meio em que é construída (sociedade, cultura, meio ambiente, política, etc.), traz um ponto frágil à busca do desenvolvimento sustentável, dado que à medida que se restringem os elementos a serem considerados na construção de uma tecnologia, priorizando lucro, por exemplo, a busca por minimizar externalidades negativas geradas por esta, ou mesmo a busca por soluções para problemas sociais, é diminuída como objetivo ou até descartada.

Tais pontos são refletidos na elaboração de políticas públicas, as quais, como mostrado ao longo do artigo, apresentam potencial para executar ações em prol do desenvolvimento sustentável. No entanto, o que se observou, na literatura analisada, foi a inclusão figurativa nos discursos e, de forma "controlada", na agenda política, dos elementos envolvidos no objetivo de se alcançar o desenvolvimento sustentável.

A política científica e tecnológica (PCT), como parte da política pública, também apresenta as mesmas características em sua elaboração, ou seja, assimila em seus textos elementos voltados ao desenvolvimento sustentável de forma controlada, ou seja, desde que tais elementos não interfiram na obtenção do lucro almejado. Dada a ligação direta aos estudos de C\&T, a participação de atores na elaboração da PCT segue, ainda, a tradição de 
envolvimento mínimo de atores que representem as necessidades reais da sociedade, minimizando o aparecimento, nas pautas, de conflitos de interesses que beneficiem as classes menos favorecidas, fazendo com que interesses da classe dominante prevaleçam.

Para o alcance do desenvolvimento sustentável, dada a sua complexidade, pela necessidade de se ponderar os objetivos de atores diversos, muitas vezes contraditórios, o ganho de espaço nas discussões acadêmicas e políticas é considerado como relevante. Isso se deve ao fato de que, à medida que se amplia a discussão, se aumentam as possibilidades de solução para os problemas enfrentados pela sociedade atual, ou prevista para sociedades futuras, vislumbrando, assim, se modificar o modelo de desenvolvimento em vigor.

A presença do termo desenvolvimento sustentável nos discursos, de forma tão ampla, traz a ilusão de que, ao se pronunciar este, providências estão sendo tomada para se modificar a reconhecida finitude e insustentabilidade do atual desenvolvimento. Contudo, apesar de os elementos necessários para o alcance do desenvolvimento sustentável receberem cada vez mais atenção nos discursos, a prática efetiva tem sido insuficiente. Isso porque a manutenção das tomadas decisões no formato atual, que possui como foco se alcançar lucros, leva ainda a decisões de caráter puramente econômicos, o que nega, na prática, o que tem se assumido no discurso ao se ressaltar a necessidade do desenvolvimento sustentável.

A espera em se alcançar um desenvolvimento sustentável, destacada no título deste artigo, referese justamente a diferença entre o discurso e a prática. Ao mesmo tempo em que se apresenta uma imagem preocupada com o futuro nos discursos, se mantém as decisões e ações nos moldes de períodos anteriores aos estudos de CTS, protelando e até inviabilizando que o desenvolvimento sustentável seja realmente alcançado. 


\section{Referências}

BBC - Brasil. (2015). Cidade italiana proíbe forno a lenha para conter poluição. Recuperado em 29 outubro, 2016, de http://www.bbc.com/portuguese/noticias/2015/12/151225 proibicao forno lenha san vitalino Igb

Bijker, W. E., et al. (1989). The social construction of technological systems: new directions in the sociology and history of technology. Cambridge, Mass, 17-50.

Boff, L. (2015). Sustentabilidade - o que é: o que não é (4a ed.). Vozes: Petrópolis.

Cavalcanti, C. (2001). Meio ambiente, desenvolvimento sustentável e políticas públicas. Cortez.

Cerezo, J. A. L. (2004). Ciência, Tecnologia e Sociedade: o Estado da Arte na Europa e nos Estados Unidos. In: Santos et al. (eds.) Ciência, Tecnologia e Sociedade. O desafio da interação. IAPAR, Londrina.

Cutcliffe, S. H. (2003). La emergencia de CTS como campo acadêmico. In: Ideas, Máquinas y Valores. Los Estudios de Ciencia, Tecnología y Sociedad. Anthropos, Barcelona.

Dias, R. B. (2011). O que é a política científica e tecnológica? Sociologias, Porto Alegre, 13(28), 316-344.

Dye, T. D. (1984). Understanding Public Policy. Englewood Cliffs, N.J.: Prentice-Hall.

Feenberg, A. (2010). Do essencialismo ao construtivismo: a filosofia da tecnologia em uma encruzilhada. In: Neder, Ricardo T. (org.) A teoria crítica de Andrew Feenberg: racionalização democrática, poder e tecnologia. Brasília: Observatório do Movimento pela Tecnologia Social na América Latina / CDS / UnB / Capes, 205 251.

Feenberg, A. (2007). Incommensurable Paradigms: Values and the Environment, In: Revue du MAUSS. Recuperado em 30 Outubro, 2016, de: http://www.journaldumauss.net/?Incommensura ble-Paradigms-Values

Gibbons, M.; et al. (1994). The new production of knowledge: the dynamics of science and research in contemporary societies. London: SAGE Publications.

Hughes, T. P. (1989). The evolution of large technological systems. In: BIJKER, Wiebe E. et al (eds.). The social construction of technological systems: new directions in the sociology and history of technology. Cambridge, Mass.: MIT Press, 51 - 82

Kreimer, P. (2009) El Científico Tambíem es un Ser Humano. Buenos Aires: Siglo Veinteuno Editores.

Laswell, H. D. (1958). Politics: who gets what, when, how. Cleveland, EUA: Meridian Books.

Lynn, L. E. (1980). Designing Public Policy: a casebook on the role of policy analysis. Santa Monica, EUA: Goodyear. Mead, L. M. (1995). Public Policy: Vision, Potential, Limits. Policy Currents, 1-4.

Neder, R. T. (2010). A teoria crítica de Andrew Feenberg: racionalização democrática, poder e tecnologia. Brasília: Observatório do Movimento pela Tecnologia Social na América Latina / CDS / UnB / Capes.

Peters, B. G. (1986). American Public Policy. Chatham, EUA: Chatham House.

Sachs, I. (2002). Caminhos para o desenvolvimento sustentável (2a Ed.). Rio de Janeiro: Garamond.

Souza, C.; et al. (2006). Políticas públicas: uma revisão da literatura. Sociologias, 8(16), 20-45.

Van Bellen, H. M. (2006). Indicadores de sustentabilidade: uma análise comparativa. Rio de Janeiro: FGV Editora.

Vieira Pinto, A. (2005). A tecnologia. In: O Conceito de Tecnologia, 1. Rio de Janeiro: Contraponto. 
Viotti, E. B. (2008). Brasil: de política de C\&T para política de inovação? Evolução das políticas brasileiras de ciência, tecnologia e inovação. In: Velho, L.; Souza Paula, M. C. (orgs.). Avaliação de políticas de ciência, tecnologia e inovação: diálogo entre experiências internacionais e brasileiras. Brasília: Centro de Gestão e Estudos Estratégicos. 